\title{
Fractionation and Identification of Volatile Compounds in Patis, a Philippine Fish Sauce
}

\author{
Norlita G. Sanceda, Tadao Kurata and Nobuhiko Arakawa \\ Department of Food and Nutrition, \\ Ochanomizu University, Bunkyo-ku, Tokyo 112, Japan
}

Received May 16, 1984

\begin{abstract}
Commercial Philippine fish sauce (Patis) was steam-distilled and the distillate was fractionated into four fractions, neutral, basic, acidic and phenolic and each fraction was analyzed using gas chromatography and gas chromatography-mass spectrometry.

As a result of this study, a total of 66 compounds were identified in Patis, 14 of which were only a tentative identification. Out of these 66 identified compounds, 40 identified compounds have not been reported in previous studies on fish sauces. These identified compounds include 19 acids, 14 alcohols, 12 nitrogen containing compounds, 5 esters, 3 sulfur containing compounds, 1 phenol, 3 carbonyls, 7 hydrocarbons and 2 others. In the acidic fraction, 5 acids were considered major constituents which accounted for about $98 \%$ of the total acids. $n$-Butanoic acid was found to be the most abundant accounting for about $50 \%$ of the total acids.
\end{abstract}

Fish sauce plays a major role in the utilization of fishes in Southeast Asia. It is a clear brown liquid produced from a mixture of 3 parts fish to $1 \sim 2$ parts salt and allowed to ferment from six to twelve months. It is a commonly used food condiment in the diet of many of the Southeast Asian people.

It has been reported that the aroma of fish sauce is composed of a blend of ammoniacal, cheesy and meaty notes. ${ }^{1)}$ A variety of amines, ammonia and other nitrogen containing compounds have been attributed to the ammoniacal note as described by Dougan and Howard and Saisithi et al. ${ }^{2)}$ Truong Van Chom ${ }^{3)}$ considered volatile fatty acids such as formic, acetic and $n$-butanoic acids as contributory factors in the aroma of fish sauce. Investigation of Noucmam, a Vietnamese fish sauce revealed that it contains a large amount of methyl ketones which probably accounts for the cheesy odor. ${ }^{4)}$ The meaty note is complicated but it was believed that it could be produced by atmospheric oxidation of precursors that were still present in mature sauces. $^{1)}$

In our previous paper, ${ }^{5)}$ it was reported that acids are partly responsible for the cheesy and rancid odor of Philippine fish sauce (Patis). $n$ Butanoic acid was found to be the most abundant acid in fish sauce ${ }^{2,5,6)}$ whereas McIver et $a l{ }^{7)}$ reported that acetic acid is the major acid in Nampla, a Thai fish sauce.

The present study was carried out to identify additional volatile aroma compounds in fish sauce by using gas chromatography and gas chromatography-mass spectrometry.

\section{MATERIALS AND METHODS}

Commercial fish sauce (Patis) in glass bottles obtained in the Philippines in 1982 was used.

Collection of volatile aroma compounds by steam distillation. Samples were steam-distilled under reduced pressure at a temperature maintained at $45^{\circ} \mathrm{C}$ for about four hours. The whole steam volatile distillate obtained was extracted with ethyl ether. The extract was then dried by adding anhydrous sodium sulfate and allowed to stand overnight to ensure complete removal of water. It was concentrated to about $0.5 \mathrm{ml}$ at $30^{\circ} \mathrm{C}$ under atmospheric pressure to give a whole steam volatile concentrate ready for analysis. For the execution and interpretation of subsequent analyses, the distillate was fractionated into four fractions, neutral, basic, acidic and phenolic fractions using the procedure explained in Fig. 1. Each of the four fractions was concentrated using the same procedure explained above. 


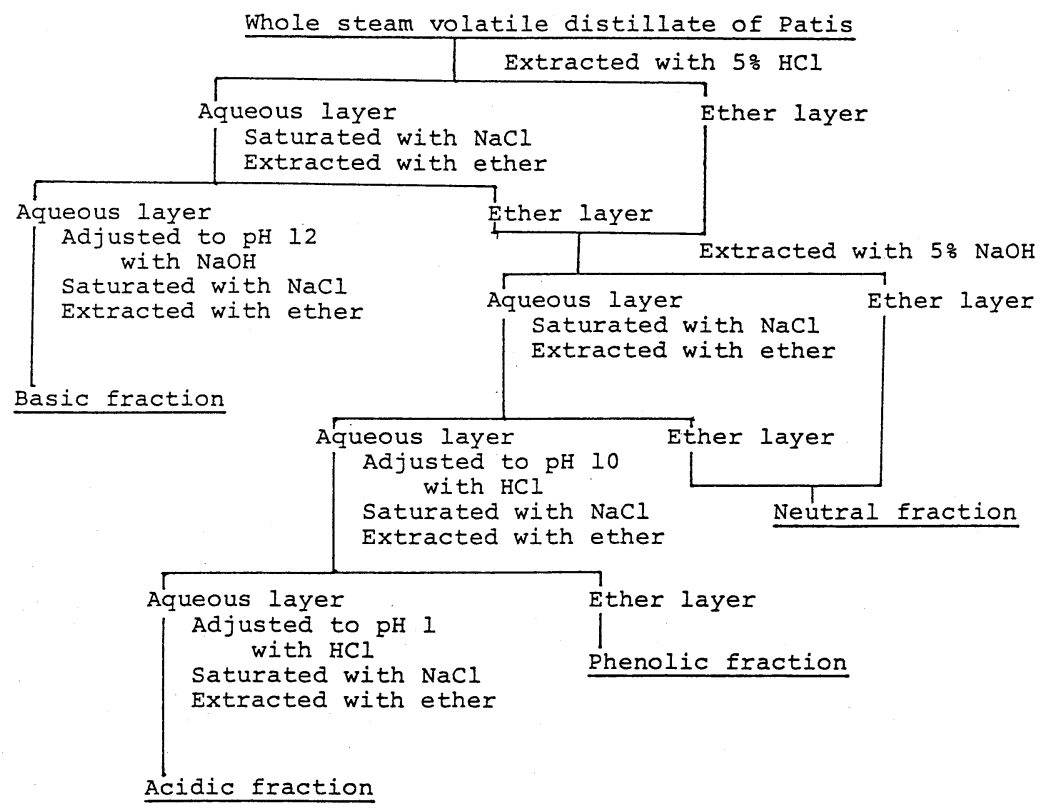

FIG. 1. Fractionation of Whole Steam Volatile Distillate of Patis.

Gas chromatography $(G C)$. For the separation of flavor compounds, the concentrate of each fraction was analyzed with a Hitachi 663-30 model gas chromatograph equipped with a flame ionization detector (FID). A fused silica capillary column $(0.25 \mathrm{~mm}$ i.d. $\times 25 \mathrm{~m})$ coated with PEG $20 \mathrm{M}$ was used. The column temperature was programmed from $60^{\circ} \mathrm{C}$ to $170^{\circ} \mathrm{C}$ at a rate of $4^{\circ} \mathrm{C} / \mathrm{min}$ and the injection port and detector were kept at $180^{\circ} \mathrm{C}$ and $230^{\circ} \mathrm{C}$ respectively. Nitrogen was used as carrier gas with a flow rate of about $1.0 \mathrm{ml} / \mathrm{min}$. Split ratio was $1: 40$.

Gas chromatography-mass spectrometry (GC-MS). A Hewlett Packard 5790 model gas chromatograph with a fused silica capillary column $(0.25 \mathrm{~mm}$ i.d. $\times 50 \mathrm{~m})$ coated with carbowax $20 \mathrm{M}$ was used. The column temperature was programmed from 60 to $170^{\circ} \mathrm{C}$ at a rate of $4^{\circ} \mathrm{C} / \mathrm{min}$, the injection port at $180^{\circ} \mathrm{C}$ and the detector at $230^{\circ} \mathrm{C}$. The carrier gas was Helium with a flow rate of about $1.1 \mathrm{ml} / \mathrm{min}$ and a split ratio of $1: 28$. The mass spectrometer JEOL JMS-DX 300 model was used. Analysis was conducted using two kinds of ionization methods, the chemical ionization method (CI) and the electron ionization method (EI), the latter was done at $70 \mathrm{eV}$. Interface temperature was maintained at $200^{\circ} \mathrm{C}$.

Identification of aroma compounds. Aroma compounds were tentatively identified by comparing their mass spectra with the published spectra ${ }^{10}$ and further confirmed by comparing their retention times with those of the standard samples using gas chromatography.
Determination of amounts of acids. The relative amount of each acid was tentatively determined by the estimation of the peak area with an integrator Shimadzu Chromatopac C-R1a.

\section{RESULTS AND DISCUSSION}

In our previous paper, ${ }^{5)}$ sensory evaluation study showed that the whole steam volatile concentrate of Patis is composed of a blend of various aromas. In the acidic fraction, 16 volatile acids were identified and $n$-butanoic acid appeared to be the most abundant. This fraction was described as having a cheesy, rancid and disagreeable odor. ${ }^{5}$ As a result of the quantitative analysis of acids in the acidic fraction, 5 were considered as major acids which collectively accounted for about $98 \%$ of the total acids (Table I). $n$-Butanoic acid composed about $50 \%$ of the total acids while propanoic acid accounted for $22 \%$, isopentanoic acid $17 \%$, and acetic and isobutanoic acids about 4 and $3 \%$ respectively. $n$-Butanoic acid is characterized to have a disagreeable odor. The minor acids, which also included the newly identified ones, benzonic acid and tentatively identified 5-hexenoic and 2,5-dihy- 
Table I. Major Acids In the Acidic Fraction OF Patis

\begin{tabular}{lc}
\hline Compounds & $\begin{array}{c}\% \text { of } \\
\text { fraction }^{a}\end{array}$ \\
\hline Acetic & 3.8 \\
Propanoic & 22.2 \\
Isobutanoic & 3.3 \\
n-Butanoic & 51.3 \\
Isopentanoic & 17.4 \\
\hline
\end{tabular}

a Percent of fraction values are computed on an area percent basis.

drobenzoic acids, each present at less than $1 \%$ of the total fraction are given in the list of all the identified compounds presented in Table II.

It was reported that the ratio of acetic acid to $n$-butanoic acid was found to be $1: 1$ in Noucmam, whereas for a good quality Nampla, this ratio could be as high as $20: 1 .^{8}$ Truong Van Chom $^{3)}$ also found approximately equal amounts of acetic acid and $n$-butanoic acid in Vietnamese sauce. The Chinese and Hongkong fish sauces both purchased in London, were found to have a low content of volatile fatty acids thus were less cheesy and more ammoniacal. ${ }^{1)}$ Furthermore, the same author reported that the fatty acid content of the commercial Philippine fish sauce fell within the range of values obtained from the Thai sauce product. However, it is interesting to note that in this study, the ratio of acetic acid to $n$-butanoic acid was $1: 17$ which is in contrast to the findings of Nguyen-an $\mathrm{Cu}$ and Vialard-Goudou. ${ }^{8)}$ These results might suggest that there is a characteristic difference in fish sauces considering the kinds of fishes used and the methods of production.

Although $n$-butanoic acid appeared to be the most predominant volatile compound in Patis, as shown in Fig. 2, its impact on the overall aroma of fish sauce is not well pronounced. This might suggest that other volatile compounds present in the neutral, basic and phenolic fractions have a great influence on the formation of the total aroma.

In our previous study, it was reported that the neutral fraction has a sweet, somewhat burnt and rice bran like smell. ${ }^{5}$ Compounds identified in this fraction which are listed in Table II contained a number of alcohols, almost all of which appeared in low concentrations except, 2,2-dimethyl-1, 3-propanediol, benzyl alcohol and 2-phenyl ethanol, which appeared in a fairly large amount. The latter has a rose like floral aroma. Methyl ketone, considered by Van Veen to be responsible for the cheesy odor of fish sauce, ${ }^{4)}$ was found in this sauce. Phenol, also found in the phenolic fraction showed a high concentration. Other compounds identified were nitrogen containing compounds which are mostly composed of pyrazines and pyridines, compounds known to posses respectively a burnt and disagreeable odor, and they appeared at low concentrations. Ide et al. ${ }^{9)}$ also identified these compounds in their study on Thai sauce. Among the sulfur containing compounds identified, 1-ethenyl-methyl disulfide was found to appear at a high concentration but there might be a possibility that other compounds with the same retention time could have been contaminated in this peak. A few esters and carbonyls were among those identified as minor components. The presence of hydrocarbons were also observed although the identification was only tentative using gas chromatography-mass spectrometry. We could not identify aldehydes in this sample although other authors reported its presence in other fish sauces. ${ }^{6,7)}$ Dougan and Howard and Saisithi et al. ${ }^{1,2)}$ explained that aldehydes formed in the samples would have been consumed in the enzymatic browning.

The GC profile obtained in the analysis of the basic fraction indicated the presence of nitrogen containing compounds including trimethylamine which were confirmed using GCMS. This fraction was characterized to have a burnt and acetamide like smell. ${ }^{5}$ The phenolic fraction, which was reported to have a rice bran smell, ${ }^{5)}$ revealed the presence of phenol but no other phenolic compounds could be detected. This finding might support our previous report that the phenolic fraction has the 
Table II. Aroma Compounds Identified in Patis

\begin{tabular}{|c|c|c|c|c|}
\hline Peak No. & Compounds & Fraction $f$ & References $^{r}$ & $\begin{array}{l}\text { Methods of } \\
\text { identification }\end{array}$ \\
\hline \multicolumn{5}{|l|}{ Acids } \\
\hline 37 & Acetic & A & $\mathrm{a}, \mathrm{b}, \mathrm{c}, \mathrm{d}, \mathrm{e}, \mathrm{f}$ & GC-MS, $t_{R}$ \\
\hline 44 & Propanoic & A & a,c,d,e,f,h & GC-MS, $t_{R}$ \\
\hline 47 & Isobutanoic & A & $\mathrm{a}, \mathrm{c}, \mathrm{d}, \mathrm{e}, \mathrm{f}$ & GC-MS, $t_{R}$ \\
\hline 58 & $n$-Butanoic & A & $\mathrm{a}, \mathrm{b}, \mathrm{c}, \mathrm{d}, \mathrm{e}, \mathrm{f}, \mathrm{h}$ & $\mathrm{GC}-\mathrm{MS}, t_{R}$ \\
\hline 64 & Isopentanoic & A & $\mathrm{a}, \mathrm{c}, \mathrm{d}, \mathrm{e}, \mathrm{f}, \mathrm{h}$ & GC-MS, $t_{R}$ \\
\hline 69 & $n$-Pentanoic & A & $\mathrm{a}, \mathrm{f}$ & GC-MS, $t_{R}$ \\
\hline $70-\mathrm{a}^{*}$ & 5-Hexenoic & A & $* *$ & GC-MS \\
\hline 70 & Isohexanoic & A & $\mathrm{a}, \mathrm{f}$ & $\mathrm{GC}-\mathrm{MS}, t_{R}$ \\
\hline 76 & $n$-Hexanoic & A & $\mathrm{a}, \mathrm{e}, \mathrm{f}$ & $\mathrm{GC}-\mathrm{MS}, t_{R}$ \\
\hline 88 & Isoheptanoic & A & $\mathrm{a}$ & GC-MS, $t_{R}$ \\
\hline 90 & $n$-Heptanoic & A & $\mathrm{a}$ & GC-MS, $t_{R}$ \\
\hline 94 & Isooctanoic & A & a & GC-MS, $t_{R}$ \\
\hline 96 & Isononanoic & A & a & GC-MS, $t_{R}$ \\
\hline 97 & $n$-Octanoic & A & $\mathrm{a}$ & GC-MS, $t_{R}$ \\
\hline 99 & $n$-Nonanoic & A & a & GC-MS, $t_{R}$ \\
\hline 100 & Isodecanoic & A & a & GC-MS, $t_{R}$ \\
\hline 101 & $n$-Decanoic & A & a & GC-MS, $t_{R}$ \\
\hline $106^{*}$ & 2,5-Dihydrobenzoic & A & $* *$ & GC-MS \\
\hline 107 & Benzoic & A & ** & GC-MS, $t_{R}$ \\
\hline \multicolumn{5}{|l|}{ Alcohols } \\
\hline 2 & Ethanol & $\mathrm{N}$ & $e, f$ & GC-MS, $t_{R}$ \\
\hline 3 & Propanol & $\mathrm{N}$ & $\mathrm{e}$ & GC-MS, $t_{R}$ \\
\hline 9 & Butanol & $\mathrm{N}$ & $e, f$ & GC-MS, $t_{R}$ \\
\hline $18^{*}$ & 2-Methyl-2-Pentanol & $\mathrm{N}$ & $* *$ & GC-MS \\
\hline 21 & Isopentanol & $\mathrm{N}$ & $\mathrm{e}, \mathrm{h}$ & GC-MS, $t_{R}$ \\
\hline 38 & Heptanol & $\mathrm{N}$ & $* *$ & GC-MS, $t_{R}$ \\
\hline 40 & 2-Octanol & $\mathrm{N}$ & $* *$ & GC-MS, $t_{R}$ \\
\hline 43 & 1-Octanol & $\mathrm{N}$ & $* *$ & GC-MS, $t_{R}$ \\
\hline 52 & Nonanol & $\mathbf{N}$ & $* *$ & GC-MS, $t_{R}$ \\
\hline 54 & Decanol & $\mathrm{N}$ & $* *$ & GC-MS, $t_{R}$ \\
\hline 59 & Furfuryl alcohol & $\mathrm{N}$ & $* *$ & $\mathrm{GC}-\mathrm{MS}, t_{R}$ \\
\hline 78 & 2,2-Dimethyl-1,3-propanodiol & $\mathrm{N}$ & $* *$ & GC-MS, $t_{R}$ \\
\hline 82 & Benzyl alcohol & $\mathrm{N}$ & $* *$ & GC-MS, $t_{R}$ \\
\hline 85 & 2-Phenyl ethanol & $\mathrm{N}$ & $* *$ & GC-MS, $t_{R}$ \\
\hline \multicolumn{5}{|c|}{ Nitrogen containing } \\
\hline 19 & Pyridine & $\mathrm{B}, \mathrm{N}$ & $* *$ & GC-MS, $t_{R}$ \\
\hline 24 & Pyrazole & $\mathrm{B}, \mathrm{N}$ & $* *$ & GC-MS, $t_{R}$ \\
\hline 26 & 2-Ethyl pyridine & $\mathrm{B}, \mathrm{N}$ & $* *$ & GC-MS, $t_{R}$ \\
\hline 27 & 2,5-Dimethyl pyrazine & $\mathrm{B}, \mathrm{N}$ & $\mathrm{h}$ & GC-MS, $t_{R}$ \\
\hline 28 & 2,6-Dimethyl pyrazine & $\mathrm{B}, \mathrm{N}$ & $\mathrm{f}$ & GC-MS, $t_{R}$ \\
\hline 31 & Trimethyl pyrazine & $\mathrm{B}, \mathrm{N}$ & ** & GC-MS, $t_{R}$ \\
\hline 32 & Trimethylamine & B & $d, e, f$ & GC-MS, $t_{R}$ \\
\hline 33 & 2,3,5-Trimethyl pyrazine & $\mathrm{B}, \mathrm{N}$ & $\mathrm{h}$ & $\mathrm{GC}-\mathrm{MS}, t_{R}$ \\
\hline 34 & 2,5-Diethyl pyrazine & $\mathrm{B}, \mathrm{N}$ & ** & GC-MS, $t_{R}$ \\
\hline $73^{*}$ & 3-t-Butylmercapto pyridine & $\mathrm{B}, \mathrm{N}$ & $* *$ & GC-MS \\
\hline $104^{*}$ & $n$-Formyl-5-methoxy-2-indolinol & $\mathrm{B}, \mathrm{N}$ & $* *$ & GC-MS \\
\hline 105 & Indole & $\mathrm{B}, \mathrm{N}$ & $\mathrm{f}$ & GC-MS, $t_{R}$ \\
\hline \multicolumn{5}{|l|}{ Esters } \\
\hline 1 & Ethyl acetate & $\mathrm{N}$ & $* *$ & GC-MS, $t_{R}$ \\
\hline 4 & Ethyl propionate & $\mathrm{N}$ & $* *$ & GC-MS, $t_{R}$ \\
\hline 5 & Isopropyl propionate & $\mathrm{N}$ & ** & GC-MS, $t_{R}$ \\
\hline 10 & Ethyl $n$-butyrate & $\mathbf{N}$ & $* *$ & GC-MS, $t_{R}$ \\
\hline 42 & Octyl $n$-butyrate & $\mathrm{N}$ & $* *$ & GC-MS, $t_{R}$ \\
\hline
\end{tabular}


TABLE II. (continued)

\begin{tabular}{|c|c|c|c|c|}
\hline Peak No. & Compounds & Fraction $^{f}$ & References $^{r}$ & $\begin{array}{l}\text { Methods of } \\
\text { identification }\end{array}$ \\
\hline \multicolumn{5}{|c|}{ Sulfur containing } \\
\hline 8 & Dimethyl disulfide & $\mathrm{B}, \mathrm{N}$ & $* *$ & $\mathrm{GC}-\mathrm{MS}, t_{R}$ \\
\hline 72 & 1-Ethenyl methyl disulfide & $\mathrm{B}, \mathrm{N}$ & $* *$ & GC-MS, $t_{R}$ \\
\hline $103^{*}$ & 2-Methyl 4-t-butylthiophenol & $\mathrm{B}, \mathrm{N}$ & $* *$ & GC-MS \\
\hline \multicolumn{5}{|c|}{ 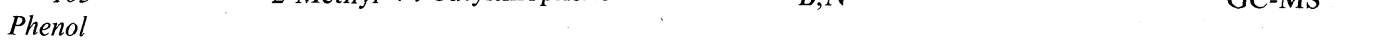 } \\
\hline 91 & Phenol & $\mathrm{P}, \mathrm{N}$ & $* *$ & GC-MS, $t_{R}$ \\
\hline \multicolumn{5}{|l|}{ Carbonyls } \\
\hline $1-b$ & Methyl ethyl ketone & $\mathrm{N}$ & $\mathrm{g}$ & GC-MS, $t^{R}$ \\
\hline 20 & Cyclopentanone & $\mathrm{N}$ & ** & GC-MS, $t_{R}$ \\
\hline 22 & 2,4-Dimethyl pentanone & $\mathrm{N}$ & ** & GC-MS, $t^{R}$ \\
\hline \multicolumn{5}{|l|}{ Hydrocarbons } \\
\hline 17 & $m$-Dimethyl benzene & $\mathrm{N}$ & ** & GC-MS, $t_{R}$ \\
\hline $23^{*}$ & cis-2-Pentene & $\mathrm{N}$ & ** & GC-MS \\
\hline $61^{*}$ & 1,1,3-Trimethyl cyclopentane & $\mathrm{N}$ & $* *$ & GC-MS \\
\hline $75^{*}$ & 2,6,10-Dimethyl octane & $\mathrm{N}$ & $* *$ & GC-MS \\
\hline $79 *$ & 2,6,10-Trimethyl tridecane & $\mathrm{N}$ & $* *$ & GC-MS \\
\hline $92^{*}$ & 2,6,10-Trimethyl hexadecane & $\mathrm{N}$ & ** & GC-MS \\
\hline $93^{*}$ & 2,6,10-Trimethyl pentadecane & $\mathrm{N}$ & ** & GC-MS \\
\hline \multicolumn{5}{|l|}{ Others } \\
\hline $25^{*}$ & Dioxane & $\mathrm{N}$ & ** & GC-MS \\
\hline $60^{*}$ & $\begin{array}{l}\text { 1,1-Bis-1-ethoxy carbonyl } \\
\text { cyclopropane }\end{array}$ & $\mathrm{N}$ & $* *$ & GC-MS \\
\hline
\end{tabular}

* Tentative identification.

** Not previously reported.

$t_{R}$ retention time.

$f$ A, acidic fraction; B, basic fraction; N, neutral fraction; $\mathrm{P}$, phenolic fraction.

r a, Sanceda et al. (1983); b, Truong Van Chom (1957); c, Dougan and Howard (1975); d, Beddows et al.(1979); e, Nonaka et al. (1975); f, McIver et al. (1982); g, Van Veen (1941); h, Ide et al. (1982).

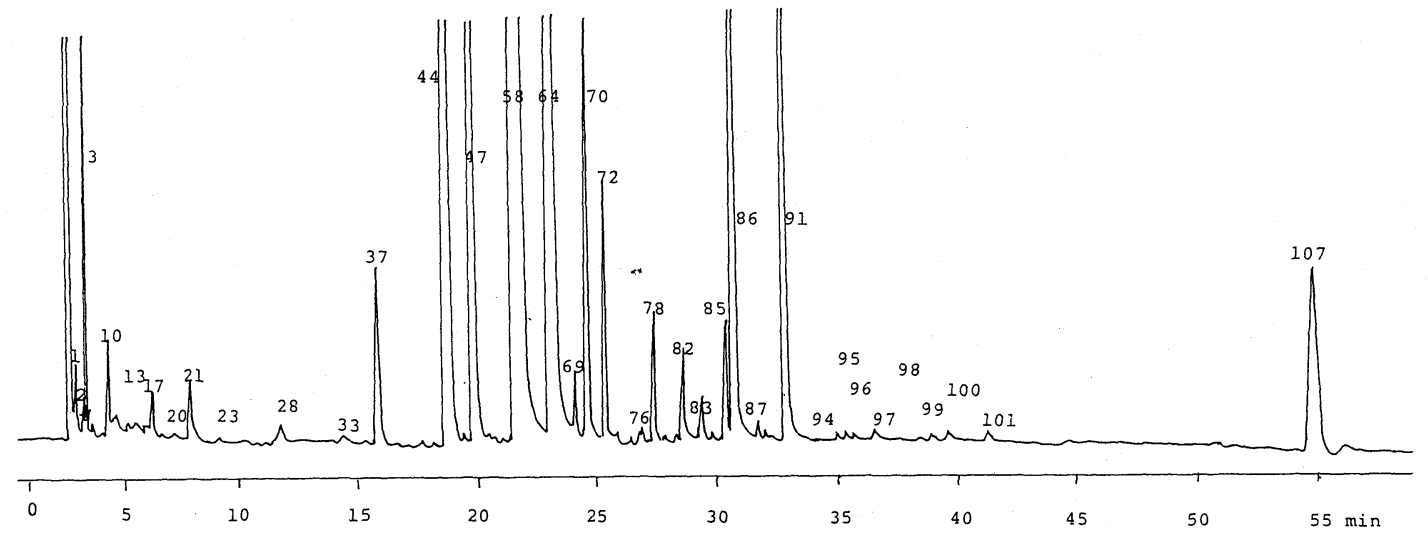

Fig. 2. Gas Chromatogram of the Whole Steam Volatile Distillate of Patis.

lowest yield among the fractions analyzed. ${ }^{5)}$

In summary, 66 compounds were identified in Patis, 14 of which were only a tentative identification. Out of these 66 compounds identified, 40 compounds have not been reported in previous studies. These identified compounds include 19 acids, 14 alcohols, 12 nitrogen containing compounds, 5 esters, 3 
sulfur containing compounds, 1 phenol, 3 carbonyls, 7 hydrocarbons and 2 others.

So far no conclusive evidence on the mechanism of the formation of volatile compounds has been reported. For further clarification, some studies on a small scale fish sauce preparation is being conducted. It is hoped that good information can be obtained from this model experiment and results will be reported in a succeeding paper.

Acknowledgment. The authors wish to thank Dr. K. Hayashi of the Kawasaki Research Laboratories, $\mathrm{T}$. Hasegawa Co. for his valuable discussion on this research.

\section{REFERENCES}

1) J. Dougan and G. Howard, Sci. Food Agric., 26, 887 (1975).
2) P. Saisithi, B. Kasensarn, J. Liston and A. Dollar, $J$. Food Sci., 31, 105 (1966).

3) T. Van Chom, Proc. 9th Pacific Sci. Congress, Vol. 5, Pacific Sci. Assoc. Bangkok, Thailand, 1957, p. 135.

4) A. G. Van Veen, Natuurwet Tijdschr Neder Indie, 101, 147 (1941a).

5) N. G. Sanceda, T. Kurata and N. Arakawa, Phil. Agr., 66, 176 (1982).

6) J. Nonaka, L. Minh Dieu and C. Koizumi, J. Tokyo Univ. Fisheries, 62, 1 (1975).

7) R. McIver, R. Brooks and G. Reineccius, J. Agric. Food Chem., 30, 1017 (1982).

8) Ng.-A. Cu, A. Vialard-Goudou, C. R. Acad. Sci., Paris, 236A, a128 (1953).

9) J. Ide, M. Nakamura, T. Yanai, J. Okumura and I. Yajima, Abstracts of Papers, Annual Meeting of Japan Agricultural Chemical Society, 1982, p. 38.

10) "Eight Peak Index Mass Spectra, 2nd Ed., Vols. $1 \sim 3$, compiled by Mass Spectrometry Data Centre, in Collaboration with ICI Ltd., 1974. 